\title{
Article \\ The Associations of Body Image Perception with Serum Resistin Levels in Highly Trained Adolescent Estonian Rhythmic Gymnasts
}

\author{
Liina Remmel ${ }^{1, *}$, Jaak Jürimäe ${ }^{1}\left(\mathbb{D}\right.$, Anna-Liisa Tamm ${ }^{2}$, Priit Purge ${ }^{1}\left(\mathbb{D}\right.$ and Vallo Tillmann ${ }^{3,4}(\mathbb{D}$ \\ 1 Institute of Sport Sciences and Physiotherapy, Faculty of Medicine, University of Tartu, 51008 Tartu, Estonia; \\ jaak.jurimae@ut.ee (J.J.); priit.purge@ut.ee (P.P.) \\ 2 Department of Physiotherapy and Environmental Health, Tartu Health Care College, 50411 Tartu, Estonia; \\ annaliisatamm@nooruse.ee \\ 3 Institute of Clinical Medicine, Faculty of Medicine, University of Tartu, 50406 Tartu, Estonia; \\ vallo.tillmann@kliinikum.ee \\ 4 Institute of Clinical Medicine, Children's Clinic of Tartu University Hospital, 50406 Tartu, Estonia \\ * Correspondence: liina.remmel@ut.ee; Tel.: +372-7375372; Fax: +372-7375373
}

Citation: Remmel, L.; Jürimäe, J.; Tamm, A.-L.; Purge, P.; Tillmann, V. The Associations of Body Image Perception with Serum Resistin Levels in Highly Trained Adolescent Estonian Rhythmic Gymnasts. Nutrients 2021, 13, 3147. https:// doi.org/10.3390/nu13093147

Academic Editor: Hisayo Yokoyama

Received: 7 July 2021

Accepted: 6 September 2021

Published: 9 September 2021

Publisher's Note: MDPI stays neutral with regard to jurisdictional claims in published maps and institutional affiliations.

Copyright: (c) 2021 by the authors. Licensee MDPI, Basel, Switzerland. This article is an open access article distributed under the terms and conditions of the Creative Commons Attribution (CC BY) license (https:// creativecommons.org/licenses/by/ $4.0 /)$.

\begin{abstract}
Rhythmic gymnasts (RGs) are more likely to be dissatisfied with their body mass and shape compared to untrained controls (UCs). However, due to the lack of information, the aim of this study was to investigate the associations of body image perception (BIP) with body composition, daily energy consumption and different blood biochemical markers in adolescent RGs compared to UCs. Thirty-three highly trained RG girls and 20 UC girls aged 14-18 years participated in this crosssectional study. Height, body mass, body composition, energy intake, resting energy expenditure, training volume and different blood biochemical markers were measured. The body attitude test (BAT) was used to evaluate the BIP of the participants. There were no differences in the total BAT scores between the groups. In RGs, the BAT score correlated positively with the serum resistin level $(\mathrm{r}=0.35 ; p=0.047)$. A stepwise multiple regression analysis showed that $40.8 \%$ of the variability in the BAT score was determined by resistin and BMI. The association of BIP with resistin values was observed only in RGs. In conclusion, our findings add to the increasing evidence that resistin may be a link between BIP and body composition, most likely through fat mass, in adolescent female RGs.
\end{abstract}

Keywords: rhythmic gymnasts; body image perception; resistin; body composition

\section{Introduction}

High-level participation in different sport events demands not only a high physical ability, but also a good mental capability [1]. Mental problems are not rare in elite athletes, with anxiety and depression being the most common disorders [1]. In comparison to other athletes, rhythmic gymnasts (RGs) are more likely to be dissatisfied and concerned with their body mass and shape [2] as visual appearance is very important in this field. Body image perception (BIP) has been associated with obesity either as a cause or as a result that affects body mass control behaviours [3]. Although BIP misperception (either underestimation or overestimation) occurs more in obese individuals [3], it has been found that RGs have a negative self-perception of their body image and their body size [4]. An inadequate energy intake is common in elite RGs [5] and may lead to a negative energy balance in these athletes [6]. Abnormal eating habits are associated with permanent worries about their body mass and BIP [7] and this is particularly pronounced during adolescencea time when RGs have high expectations for themselves and have an impaired BIP [8]. In addition, the accumulation of body fat and other pubertal changes causes their bodies to deviate from the prepubertal thin body shape considered as an ideal in this sport field, which can cause an impaired BIP among adolescent girls [9]. Given that RGs are concerned 
with their body appearance, it is important to measure their BIP and the modifiable risk factors during adolescence to prevent problems in later life.

The biochemical mechanism linking an impaired BIP and body composition is not clear. Adipokines, such as leptin, adiponectin and resistin might be possible candidates to characterise BIP by body composition variables, as positive correlations between these adipokines and BMI have been found [10]. In addition, a recent study in adolescent girls with anorexia nervosa found that the serum resistin concentration was associated with depressive symptoms [11]. Specifically, it has been suggested that resistin can inhibit dopamine and noradrenaline release in the hypothalamus and can decrease intrasynaptic monoamine levels, which in turn could lead to the predisposition of the development of depression symptoms [12]. Accordingly, this may suggest that resistin could be involved in the regulation of emotions and behaviours. We set up a study to describe body image perception (BIP) in highly trained adolescent RGs compared to UCs and the associations of BIP with body composition, daily energy consumption and different blood biochemical markers including resistin.

\section{Methods}

\subsection{Participants}

The participants of this study were 53 young female adolescents aged 14 to 18 years who were divided into two groups: rhythmic gymnasts (RGs; $n=33$ ) and untrained controls (UCs; $n=20)$. All UCs were eumenorrheic females who reported to have regular menstrual cycles during the last six months. In the RG group, 22 girls were eumenorrheic and 11 girls had secondary amenorrhea. Menstruating athletes and UCs were examined during the follicular phase when blood samples were obtained between 7 and 11 days from the onset of menstruation [13]. The first testing session consisted of blood sampling, dietary assessment and the completion of questionnaires about BIP and training characteristics. The second testing session consisted of resting energy expenditure (REE) and body composition assessments. All subjects and their parents had to sign an informed consent. The Medical Ethics Committee of the University of Tartu, Estonia (ethical approval code number 274/T-3, date 16 October 2017) approved the current study.

\subsection{Medical and Menstrual History}

Information about the age at menarche, changes in menstrual cycle, possible oral contraceptive use, past and current illnesses, use of medications, vitamins and food supplements were collected [13]. Regular menstrual cycles were defined as menses occurring every 24-35 days [13]. Secondary amenorrhea was classified as the absence of at least three consecutive menstrual cycles after the initiation of menses, including no regular menses for at least six months [14].

\subsection{Body Composition}

The participants' body height (Martin metal anthropometer) and body mass (A\&D Instruments Ltd., Abingdon, UK) were measured to the nearest $0.1 \mathrm{~cm}$ and $0.05 \mathrm{~kg}$, respectively. The calculation of the body mass index (BMI) was completed as a ratio of body mass to the height squared $\left(\mathrm{kg} / \mathrm{m}^{2}\right)$. The dual-energy X-ray absorptiometry (DXA) using the DPX-IQ densitometer (Lunar Corporation, Madison, WI, USA) equipped with proprietary software, version 3.6 was used to measure the body composition of the participants. All participants were scanned in light clothing. They were laid flat on their backs, arms on their sides and were motionless. Total body (TB) fat mass (FM; kg) and lean body mass ( $\mathrm{LBM} ; \mathrm{kg}$ ) were measured and the TB FM\% was calculated. The same examiner conducted the DXA measurements and evaluated the results. The coefficients of variations (CVs) for the obtained results were less than $2 \%$. 


\subsection{Dietary Assessment}

Energy and nutrient intakes were assessed using the average of three $24 \mathrm{~h}$ dietary recalls. It had to include two weekdays (i.e., Thursday and Friday) and one weekend day (Saturday). All participants were instructed to keep their ordinary diet where they were allowed to eat as much as they ate usually during the study period but were asked to maintain their usual dietary habits and everyday physical activities as before the assessment [15] To evaluate estimated portion sizes, cup and bowl sizes were used. The Nutridata System for Research (www.nutridata.ee; accessed on January 2018; National Institute for Health Development, Tallinn, Estonia) was used to analyze the results. The dietary analysis included energy, carbohydrates, proteins, fats, vitamin D, vitamin C, calcium, magnesium, potassium, iron and sodium. Total daily food intake was also included in the analysis. The daily energy and nutrient intakes were calculated as the average of the three days [15].

\subsection{Resting Energy Expenditure}

Resting energy expenditure (REE) was measured in the morning after an overnight fast. Participants were asked to avoid different kinds of intense physical activity for the $24 \mathrm{~h}$ period before the REE measurement. After voiding, the subjects laid down for $15 \mathrm{~min}$ before the measurement of oxygen consumption $\left(\mathrm{VO}_{2}\right)$ and carbon dioxide production $\left(\mathrm{VCO}_{2}\right)$ over a $30 \mathrm{~min}$ period. The first $5 \mathrm{~min}$ and last $5 \mathrm{~min}$ of the measurement were removed to obtain an adequate result [16]. A portable open circuit spirometry system (MetaMax 3B, Cortex Biophysic GmbH, Germany) was used, the data were recorded in $10 \mathrm{~s}$ intervals and the mean of the $20 \mathrm{~min}$ was used to calculate REE according to Weir's equation (1949): Basal metabolic rate $(\mathrm{BMR})(\mathrm{kcal} / \mathrm{min})=3.9\left[\mathrm{VO}_{2}(\mathrm{l} / \mathrm{min})\right]+1.1\left[\mathrm{VCO}_{2}\right.$ $(\mathrm{l} / \mathrm{min})] ; \operatorname{REE}(\mathrm{kcal} /$ day $)=\mathrm{BMR} \times 1440 \mathrm{~min}[17]$.

\subsection{Blood Analysis}

A venous blood sample was collected between 8:00 and 9:00 a.m. from an antecubital vein. The blood serum was separated and then frozen at $-80{ }^{\circ} \mathrm{C}$ for later analysis. Serum ferritin, insulin, leptin, interleukin-6 (IL-6), plasminogen activator inhibitor-1 (PAI-1), resistin and tumor necrosis factor-a (TNF-a) levels were measured using "Metabolic Syndrome Array I" kit by Evidence ${ }^{\circledR}$ Biochip Technology (Randox Laboratories Ltd., Crumlin, UK). None of the metabolic biomarkers were below the detection limits. The intra-assay coefficient of variation (CV) was between 2 and $5 \%$ and the inter-assay $\mathrm{CV}$ was between 8.2 and $11.5 \%$ for all measured markers.

\subsection{Body Attitude Test}

During the first testing session, the subjects filled out a body attitude test (BAT) (Appendix A) to evaluate their body image perception (BIP) [18]. The BAT is intended for female subjects to measure their subjective body experience and their attitude towards their body as BIP. Specifically, the BAT consists of 20 items to be scored on a 6-point Likert scale from never to always. The higher the score, the more the body experience deviates. In addition to the total score, subscales of factor 1 (negative appreciation of body size), factor 2 (lack of familiarity with one's own body), factor 3 (general body dissatisfaction) and the rest factor were calculated [18].

The cut-off point above 36 was used to identify subjects with a very high likelihood of having eating disorders and an impaired BIP [19].

\subsection{Statistical Analysis}

All statistical analyses were completed using SPSS softwere version 21.0 package for Windows (Chicago, IL, USA). Standard statistical methods were used to calculate the means and standard deviations (SD). The Shapiro-Wilk method was used to evaluate the normality of the data. Data that were not normally distributed were logarithmically transformed prior to the analysis to approximate a normal distribution. The differences between the BAT scores and the measured biomarkers were evaluated using an independent $t$-test. 
In addition, effect size (ES) was calculated as the pairwise comparison of quantitative variables and was considered to be small if ES > 0.1, moderate if ES > 0.3 or large if ES $>0.5$. The odd ratio (OD) was calculated as a chi squared test for detecting any possible statistical differences of an impaired BIP. Spearman correlations were conducted to describe the relationships between the variables. A stepwise multiple regression analysis was performed to determine the independent effect of body height, body mass, BMI, body composition characteristics and different blood biochemical characteristics on the BAT scores. The significance level was set at $p<0.05$.

\section{Results}

The studied RG and UC groups had similar body height, body mass and BMI values (Table 1). As expected, in the RGs the TB FM\% and TB FM values were lower $(p<0.05)$ and the TB LBM was higher compared to the UCs. The mean energy intake and REE were similar between the groups (Table 1). In addition, insulin, leptin, IL-6 and PAI-1 levels were significantly lower in the RG compared to the UC group (Table 2).

Table 1. The main characteristics and fat parameter data in the rhythmic gymnasts (RGs) and untrained controls (UCs) female groups.

\begin{tabular}{|c|c|c|c|c|}
\hline & RG (33) & UC (20) & $p$ Value & ES \\
\hline Age (yrs) & $16.0 \pm 1.2$ & $16.5 \pm 1.6$ & 0.202 & 0.39 \\
\hline Body height (cm) & $166.8 \pm 5.3$ & $166.8 \pm 5.0$ & 0.976 & 0.01 \\
\hline Body mass $(\mathrm{kg})$ & $55.7 \pm 7.0$ & $58.4 \pm 7.4$ & 0.180 & 0.42 \\
\hline $\operatorname{BMI}\left(\mathrm{kg} / \mathrm{m}^{2}\right)$ & $20.0 \pm 2.0$ & $21.0 \pm 2.2$ & 0.100 & 0.52 \\
\hline TB FM $\%(\%)$ & $19.6 \pm 5.7^{*}$ & $30.4 \pm 6.2$ & $<0.001$ & 1.55 \\
\hline TB FM (kg) & $11.2 \pm 4.3^{*}$ & $17.8 \pm 4.8$ & $<0.001$ & 1.36 \\
\hline TB LBM (kg) & $42.2 \pm 4.1 *$ & $37.7 \pm 3.7$ & $<0.001$ & 1.06 \\
\hline Energy intake (kcal/day) & $1644.2 \pm 424.0$ & $1571.7 \pm 295.5$ & 0.505 & 0.15 \\
\hline REE (kcal/day) & $1495.0 \pm 208.1$ & $1520.3 \pm 208.3$ & 0.669 & 0.12 \\
\hline Menarcheal age (yrs) & $13.6 \pm 1.2 *$ & $12.5 \pm 0.7$ & $<0.001$ & 1.03 \\
\hline Training experience (yrs) & $10.3 \pm 0.9 *$ & - & - & - \\
\hline Training duration (h/week) & $17.6 \pm 5.3^{*}$ & $2.1 \pm 1.3$ & $<0.001$ & 1.84 \\
\hline
\end{tabular}

BMI, body mass index; TB FM, total body fat mass; TB LBM, total body lean body mass; REE, resting energy expenditure; ES, effect size. Data are described by means \pm SD. Significant $(p<0.05)$ difference between RGs and UCs *. ES is small if ES >0.1, moderate if $E S>0.3$ or large if ES $>0.5$.

Table 2. The blood biomarkers data in the RGs and UCs female groups.

\begin{tabular}{ccccc}
\hline & RG (33) & UC (20) & $p$ Value & ES \\
\hline Ferritin $(\mathrm{ng} / \mathrm{mL})$ & $35.84 \pm 14.53$ & $24.68 \pm 23.79$ & 0.038 & 0.55 \\
\hline Insulin $(\mathrm{ulU} / \mathrm{mL})$ & $6.12 \pm 2.27^{*}$ & $8.65 \pm 3.54$ & 0.002 & 0.90 \\
\hline Leptin $(\mathrm{ng} / \mathrm{mL})$ & $1.23 \pm 0.62^{*}$ & $4.29 \pm 3.40$ & $<0.001$ & 1.34 \\
\hline IL-6 $(\mathrm{pg} / \mathrm{mL})$ & $0.79 \pm 0.60^{*}$ & $1.59 \pm 1.23$ & 0.003 & 0.59 \\
\hline PAI-1 $(\mathrm{ng} / \mathrm{mL})$ & $17.85 \pm 7.10^{*}$ & $31.46 \pm 13.61$ & $<0.001$ & 1.20 \\
\hline Resistin $(\mathrm{ng} / \mathrm{mL})$ & $4.57 \pm 2.02$ & $5.67 \pm 2.37$ & 0.077 & 0.53 \\
\hline TNF-a $(\mathrm{pg} / \mathrm{mL})$ & $5.61 \pm 1.38$ & $6.41 \pm 1.60$ & 0.059 & 0.51 \\
\hline
\end{tabular}

IL-6, interleukin-6; PAI-1, plasminogen activator inhibitor-1; TNF-a, tumor necrosis factor-a. Data are described by means \pm SD. Significant $(p<0.05)$ difference between RGs and UCs ${ }^{*}$. ES is small if ES $>0.1$, moderate if $\mathrm{ES}>0.3$ or large if $\mathrm{ES}>0.5$. 
There were no differences in the total BAT scores and its subscales between the RG and UC groups (Table 3$)$. However, there were more girls $(8 / 33 ; 24.2 \%)$ with an impaired BIP (BAT > 36) in the RG group compared to the UC group $(3 / 20 ; 15 \%)$, but the difference was not statistically different. The RG and UC groups did not statistically differ $(p=1.000)$ in the frequency of impaired BIP and the OR = 1.07 [0.29-3.92]. When the RG and UC groups were combined, the serum resistin concentration was not different between the girls with a BAT $>36$ and those with a BAT $<36$.

Table 3. BAT characteristics data in the RGs and UCs female groups.

\begin{tabular}{ccccc}
\hline & RG (33) & UC (20) & $p$ Value & ES \\
\hline BAT & $29.6 \pm 14.9$ & $28.0 \pm 13.1$ & 0.707 & 0.11 \\
\hline BAT factor 1 & $8.7 \pm 6.4$ & $7.2 \pm 6.3$ & 0.412 & 0.24 \\
\hline BAT factor 2 & $7.0 \pm 4.6$ & $6.9 \pm 3.7$ & 0.913 & 0.03 \\
\hline BAT factor 3 & $6.8 \pm 4.0$ & $7.2 \pm 4.5$ & 0.795 & 0.08 \\
\hline BAT rest factor & $7.0 \pm 2.0$ & $7.1 \pm 2.2$ & 0.931 & 0.24 \\
\hline
\end{tabular}

BAT, body attitude test. Mean $\pm \mathrm{SD}$ are shown. $\mathrm{ES}$ is small if $\mathrm{ES}>0.1$, moderate if $\mathrm{ES}>0.3$ or large if $\mathrm{ES}>0.5$.

In the RG group, the BAT score correlated positively with the resistin level $(r=0.35$; $p=0.047$ ) (Table 4; Figure 1). In addition, the resistin level correlated negatively with TB FM $\%(r=-0.36 ; p=0.040)$ (Figure 2$)$ and positively with training duration $(\mathrm{r}=0.37$; $p=0.034$ ). The stepwise multiple regression analysis showed that $40.8 \%$ of the variability of the BAT was determined by resistin and BMI (Table 5).

In the UC group, the BAT correlated with BMI $(\mathrm{r}=0.48 ; p=0.039)$. The stepwise multiple regression analysis showed that $21.0 \%$ of the variability of the BAT was determined by total body mass (Table 5).

Table 4. Spearman correlation coefficients between BAT and different body composition variables, energy intake and blood biomarkers in the RG $(n=33)$ and UC $(n=20)$ groups.

\begin{tabular}{ccc}
\hline & RG (33) & UC (20) \\
\hline Body mass (kg) & BAT & BAT \\
BMI $\left(\mathrm{kg} / \mathrm{m}^{2}\right)$ & 0.190 & 0.402 \\
TB FM\% (\%) & 0.220 & $0.478^{*}$ \\
TB FM (kg) & 0.040 & 0.137 \\
TB LBM (kg) & 0.065 & 0.325 \\
Energy intake (kcal/day) & 0.222 & 0.360 \\
REE (kcal/day) & -0.221 & -0.211 \\
Ferritin (ng/mL) & 0.218 & 0.074 \\
Insulin (ulU/mL) & -0.001 & 0.059 \\
Leptin (ng/mL) & 0.270 & 0.279 \\
IL-6 (pg/mL) & 0.169 & 0.187 \\
PAI-1 (ng/mL) & 0.120 & 0.326 \\
Resistin (ng/mL) & 0.300 & 0.273 \\
TNF- a (pg/mL) & $0.354^{*}$ & -0.007 \\
\hline
\end{tabular}

Statistically significant correlations are shown with * $(p<0.05)$. 


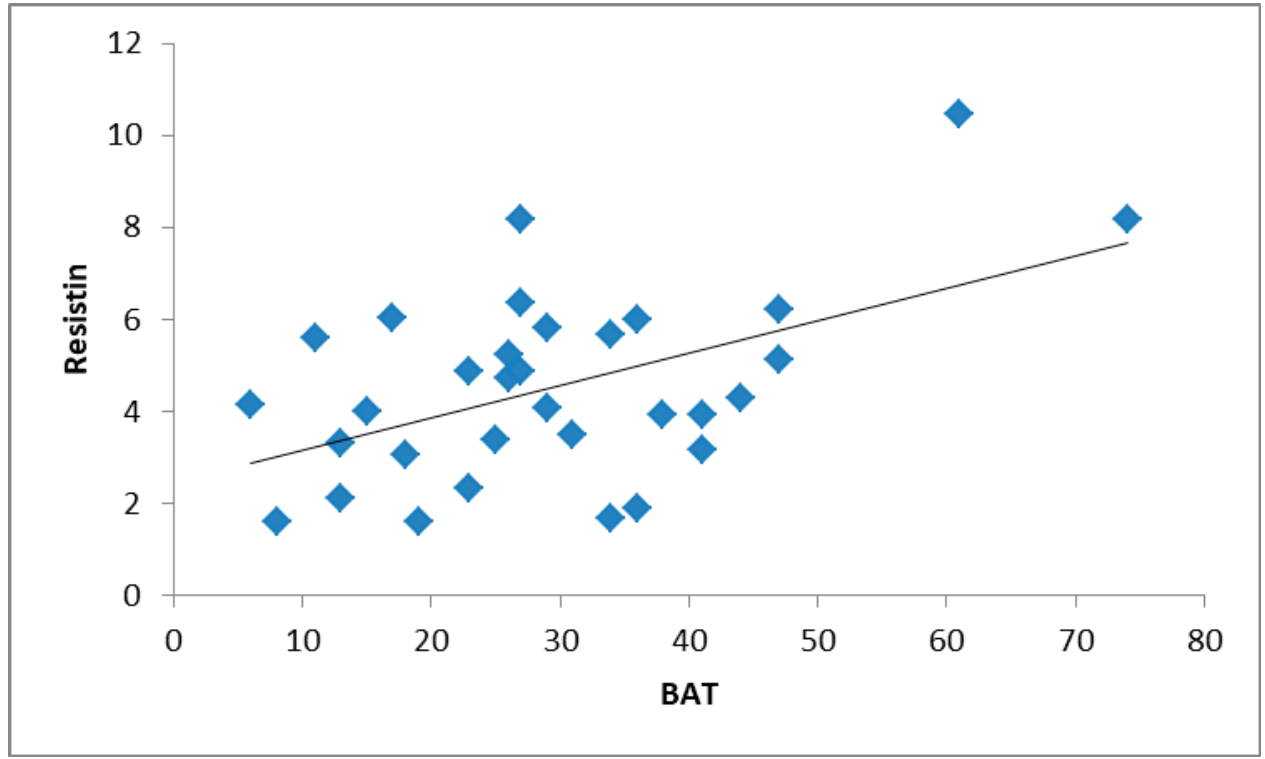

Figure 1. Correlation between resistin and BAT in RGs $(\mathrm{r}=0.35 ; p=0.047)$.

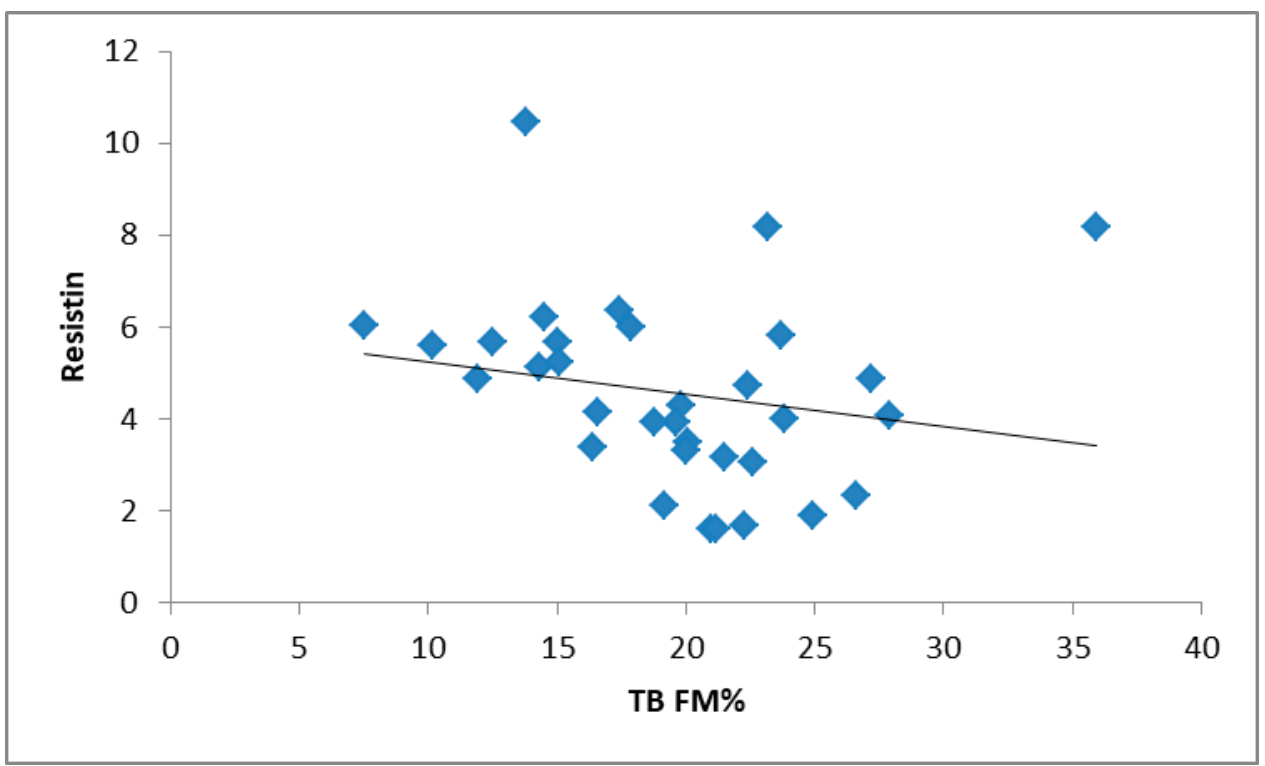

Figure 2. Correlation between resistin and TB FM \% in RGs $(r=-0.36 ; p=0.040)$.

Table 5. Results of the stepwise multiple regression analysis with BAT as the dependent variable and body height, body mass, BMI, TB FM \%, TB FM, TB LBM, energy intake, training duration, ferritin, insulin, leptin, IL-6, PAI-1, resistin and TNF-a as independent variables in RGs and UCs.

\begin{tabular}{ccc}
\hline Dependent & RG (33) & UC (20) \\
\hline & BAT & BAT \\
\hline Resistin & 24.1 & - \\
\hline Res + BMI & 40.8 & - \\
\hline Body mass & - & 21.0 \\
\hline
\end{tabular}

$\overline{\mathrm{R}^{2} \times 100 \text { is shown describing the percentage of variability of dependent variables the BAT can explain. All values }}$ are percentages. 


\section{Discussion}

This study found that nearly every fourth rhythmic gymnast (24.2\%) had an impaired body image perception (BIP) compared to every seventh girl in the untrained control group $(15 \%)$, but the difference was not statistically significant. The main finding of the current study is that the association of body image perception, measured by the body attitude test (BAT) with serum resistin values was observed in adolescent RGs. This finding suggests that serum resistin could be a link between BIP and body composition, most likely through fat mass.

It is known that young females competing in leanness and weight-class sports, such as RGs, are at a high risk of developing patterns of disordered eating, which is also associated with psychological problems in later life [20]. The prevalence of clinical eating disorders among Norwegian female elite high-intensity sport athletes was high-32.2\% [21]. Nowadays, female athletes may become increasingly attractive in the media, which is affected by society and that may be the reason the beauty ideal has emphasised visual appearance as athletic and thin [22].

Therefore, it is very important to find the girls who are at risk of these health problems and possible risk factors. Body image perception is dependent on body mass and both over- and underweight individuals have been associated with an impaired BIP [23]. In our study, $21 \%$ of the variability of the BAT score in the control girls was determined by body mass. The mean body mass of the UC group $(58.4 \mathrm{~kg}$ ) represents the 50th centile on the Estonian adolescent girl's growth chart [24] indicating that the prevalence of impaired BIP in the UC group (15\%) could represent the whole population of Estonian girls at this age. Impaired BIP is not a disease itself, but a high BAT score, a measure of BIP, could suggest a high likelihood of eating disorders later in life [19]. In addition, an impaired BIP may predict unsafe weight loss behaviours among adolescent normal weight females; thereby, excessive high-volume training to change the body appearance is associated with impaired BIP [25].

Our results showed that in RGs $24.1 \%$ of the variability of the BAT score was determined by resistin alone and $40.8 \%$ was determined by resistin together with BMI, suggesting an important role of this biomarker in BIP. We also described that the serum resistin level was positively correlated to BIP measured by the BAT. Resistin, an adipose tissue-derived low-grade inflammation marker is produced by different cells: adipocytes, macrophages, myocytes and pancreatic cells. The physiological role of resistin in humans is still unclear and studies in animals have shown different and conflicting results [12]. For instance, obesity induced by a high-fat diet or the mutation of the leptin gene or receptor is associated with increased circulating resistin concentrations, whereas resistin expression was downregulated in rodent models with diet-induced obesity and suppressed by free fatty acids [12]. In our UC group we did not find significant correlations between the serum resistin level and body mass, BMI or TB FM\%, similar to the study of 302 adolescents where the resistin level correlated with BMI, triceps skinfold, arm circumference, arm fat area and FM among obese subjects, but not in adolescents with a normal BMI [26]. However, in the RG group, the serum resistin level correlated negatively with TB FM\%. Therefore, the association between resistin and the BAT score could be mediated through body composition, most likely through FM.

In the general adult population, the resistin level has been found to have a inverse association with physical activity [27]. Our study did not find differences in the serum resistin level between the RGs and the UCs, which is similar to the study by Roupas et al. [28]. However, the training duration was significantly correlated with the resistin level in the RG group but not in the UC group. It has been suggested that rhythmic gymnastics is more likely anaerobic and therefore the long-term training has no effect on the resistin level [28].

There have been many studies linking resistin with the development of depression $[11,29,30]$. There is some evidence that resistin can inhibit dopamine and noradrenaline release in the hypothalamus and can decrease intrasynaptic monoamine levels, which could 
lead to a predisposition toward the development of depression symptoms [12]. Resistin is decreased in patients with anorexia nervosa [31]. To the best of our knowledge, no studies have examined the association of BIP with resistin and depression in RGs. Klinkowski et al. [32] showed that even though RGs may look physically similar to girls with anorexia nervosa, from the psychopathological point of view, they have very different profiles. The self-report questionnaire about psychological symptoms showed that patients with anorexia nervosa scores were significantly higher on almost all scales and no parallels in psychopathology were found between elite RGs and anorexia nervosa patients. The RG group suffered less from psychological distress than the anorexia nervosa group [32]. It has been found that depression increases significantly during adolescence, particularly in girls [33]. The association between BIP and depressive behaviours is not clear, in particular whether an impaired BIP causes depressions or whether patients with depression are more sensitive or more likely to be dissatisfied with their body image [34]. Filho et al. [35] concluded that body image dissatisfaction was associated with symptoms of a depressive disorder only in those adolescents who were dissatisfied with their body image due to being overweight, but not in those adolescents who were dissatisfied due to thinness. Probably, adolescent girls that perceived themselves to be overweight but had a normal weight are more liable to develop symptoms of a depressive disorder compared to those that had a more adequate perception of their own body mass [36]. Unfortunately, our questionnaire did not consist of questions about depression. However, different studies support the finding that resistin may be a biochemical marker linking an impaired BIP, body composition and the development of depression [29,30]. Further studies are needed before any conclusions between serum resistin level and the development of depression in high intensity trained RGs can be made.

In RGs, the average energy intake was under the energy requirements for female athletes. It is known that the recommended minimum value of the daily energy intake for female athletes is between 1800 and $2000 \mathrm{kcal}$ [37]. However, our results are similar to the study by Silva and Paiva [5], where the average daily energy intake was 1629 (kcal) in 16-18-year-old gymnasts. This finding indicates that the average daily energy intake of RGs is usually lower than the recommended figure.

To the best of our best knowledge, this is the first study investigating the associations between BIP and body composition, daily energy consumption and different blood biomarkers in RGs. In addition, the participants in this study were high level Estonian RGs from different sport clubs. These are the definite strengths of the study. However, there are also some limitations. We did not use a questionnaire about depression which would have given more details about the development of depression symptoms. In addition, the current study is cross-sectional and this limitation reduces the ability to make causal inferences.

\section{Conclusions}

Highly trained RGs did not have an impaired body image perception (BIP). The positive correlation between serum resistin level and the body attitude test as a measure of BIP, suggests that resistin may be a link between BIP and body composition in adolescent female RGs. However, further studies are needed to clarify the exact mechanism behind this association.

Author Contributions: Conceptualization, L.R., J.J., A.-L.T. and J.J.; methodology, L.R., A.-L.T. and J.J.; software, L.R.; investigation, L.R. and P.P.; resources, J.J. and V.T.; writing-original draft preparation, L.R.; writing — review and editing, J.J., A.-L.T., P.P. and V.T.; project administration, L.R.; funding acquisition, J.J. and V.T. All authors have read and agreed to the published version of the manuscript.

Funding: This research was funded by the Estonian Ministry of Education and Science Institutional Grant PRG 1120. 
Institutional Review Board Statement: The study was conducted according to the guidelines of the Declaration of Helsinki and approved by the Research Ethics Committee of the University of Tartu (ethical approval code number 274/T-3).

Informed Consent Statement: Informed consent was obtained from all subjects involved in the study.

Data Availability Statement: The data presented in this study are available on a request from the corresponding author for researchers who meet the criteria for access to confidential data.

Acknowledgments: We gratefully acknowledge all participating subjects for their collaboration. We also acknowledge all the members involved in the field work for their efforts and great enthusiasm.

Conflicts of Interest: The authors declare no conflict of interest.

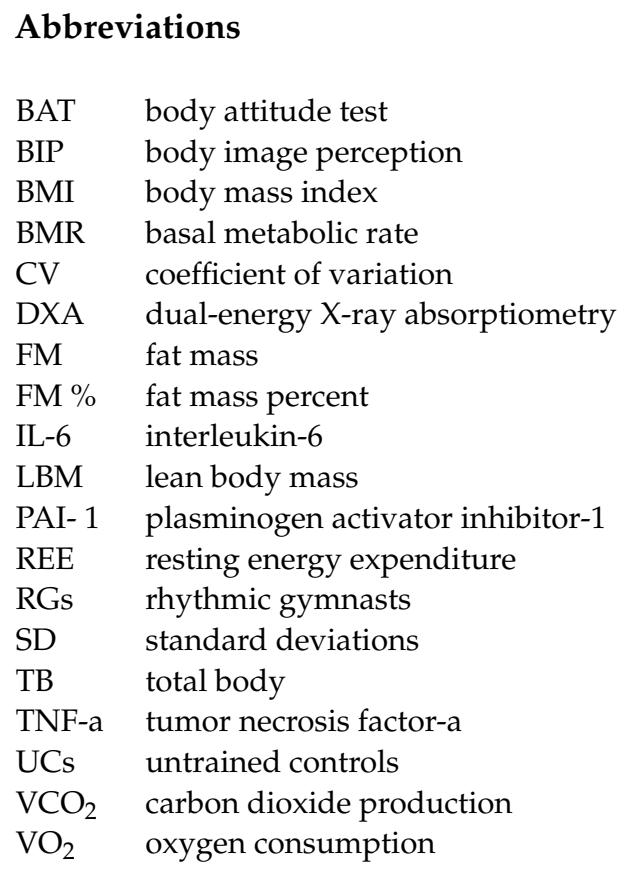

Appendix A. Body Attitude Test

Table A1. BODY-ATTITUDE-TEST (BAT).

\begin{tabular}{|c|c|c|c|c|c|c|c|}
\hline & & Always & Usually & Often & Sometimes & Rarely & Never \\
\hline 1 & $\begin{array}{l}\text { When I compare myself with my peers' bodies, I'm } \\
\text { dissatisfied with my own }\end{array}$ & & & & & & \\
\hline 2 & My body appears to be a numb thing & & & & & & \\
\hline 3 & My hips seem too broad to me & & & & & & \\
\hline 4 & I feel comfortable within my own body & & & & & & \\
\hline 5 & I have a strong desire to be thinner & & & & & & \\
\hline 6 & I think my breasts are too large & & & & & & \\
\hline 7 & I'm inclined to hide my body (e.g., by loose clothing) & & & & & & \\
\hline 8 & $\begin{array}{l}\text { When I look at myself in the mirror, I'm dissatisfied } \\
\text { with my own body }\end{array}$ & & & & & & \\
\hline 9 & It's easy for me to relax physically & & & & & & \\
\hline 10 & I think I'm too thick & & & & & & \\
\hline 11 & I feel my body as a burden & & & & & & \\
\hline 12 & My body appears as if it is not mine & & & & & & \\
\hline 13 & Some parts of my body look swollen & & & & & & \\
\hline 14 & My body is a threat for me & & & & & & \\
\hline 15 & My bodily appearance is very important to me & & & & & & \\
\hline 16 & My belly looks as if I am pregnant & & & & & & \\
\hline 17 & I feel tense in my body & & & & & & \\
\hline 18 & I envy others for their physical appearance & & & & & & \\
\hline 19 & There are things going on in my body that frighten me & & & & & & \\
\hline 20 & I am observing my appearance in the mirror & & & & & & \\
\hline
\end{tabular}




\section{References}

1. Kerr, Z.Y.; de Freese, J.D.; Marshall, S.W. Current physical and mental health of former collegiate athletes. Orthop. J. Sports Med. 2014, 2, 2325967114544107. [CrossRef] [PubMed]

2. Blagrove, R.C.; Bruinvels, G.; Read, P. Early sport specialization and intensive training in adolescent female athletes. Strength Cond. J. 2017, 39, 14-23. [CrossRef]

3. He, Z.-H.; Li, M.-D.; Liu, C.-J.; Ma, X.-Y. Relationship between body image, anxiety, food-specific inhibitory control, and emotional eating in young women with abdominal obesity: A comparative cross-sectional study. Arch. Pub. Health 2021, 79, 11. [CrossRef] [PubMed]

4. Sundgot-Borgen, J.; Meyer, N.L.; Lohman, T.G.; Ackland, T.R.; Maughan, R.J.; Stewart, A.D.; Muller, W. How to minimize the health risks to athletes who compete in weight sensitive sports: Review and position statement of the research working group on body composition, health and performance (IOC Medical Commission). Br. J. Sports Med. 2013, 47, 1012-1022. [CrossRef]

5. Silva, M.-R.G.; Paiva, T. Low energy availability and low body fat of female gymnasts before an international competition. Eur. J. Sports Sci. 2015, 15, 591-599. [CrossRef]

6. Michopoulou, E.; Avloniti, A.; Kambas, A.; Leontsini, D.; Michalopoulou, M.; Symeon, T.; Ioannis, G.F. Elite premenarcheal rhythmic gymnasts demonstrate energy and dietary intake deficiencies during periods of intense training. Pediatr. Exerc. Sci. 2011, 23, 560-572. [CrossRef]

7. Francisco, R.; Alarcao, M.; Narciso, I. Aesthetic sports as high-risk contexts for eating disorders-young elite dancers and gymnasts perspectives. Span. J. Phychol. 2012, 15, 265-274. [CrossRef]

8. Dallas, G.; Dallas, D.; Simatos, J. Nutritional status and dietary assessment of elite female artistic and rhytmic gymnasts- a case study. Sci. Gymnast. J. 2016, 8, 255-269.

9. Mousa, T.Y.; Mascal, R. Negative Body Image Perception and Associated Attitudes in Females. Body Image: Perceptions, Interpretations, and Attitudes, 15th ed.; Greene, S.P., Ed.; Nova Science Publishers: Jordan, Israel, 2011; pp. 255-261.

10. Meier, U.; Gressner, A.M. Endocrine regulation of energy metabolism: Review of pathobiochemical and clinical chemical aspects of leptin, ghrelin, adiponectin, and resistin. Clin. Chem. 2004, 50, 1511-1524. [CrossRef]

11. Tyszkiewicz-Nwafor, M.; Slopien, A.; Dmitrzak-Weglarz, M.; Rybakowski, F. Adiponectin and resistin in acutely ill and weightrecovered adolescent anorexia nervosa: Association with psychiatric symptoms. World J. Biol. Psychiatry 2018, $20,723-731$. [CrossRef] [PubMed]

12. Taylor, V.H.; MacQueen, G.M. The role of adipokines in understanding the associations between obesity and depression. J. Obes. 2010, 2010, 748048. [CrossRef]

13. Vaiksaar, S.; Jürimäe, J.; Mäestu, J.; Purge, P.; Kalytka, S.; Shakhlina, L.; Jürimäe, T. No effect of menstrual cycle phase and oral contraceptive use on endurance performance in rowers. J. Strength Cond. Res. 2011, 25, 1571-1578. [CrossRef] [PubMed]

14. Christo, K.; Cord, J.; Mendes, N.; Miller, K.K.; Goldstein, M.A.; Klibanski, A.; Misram, M. Acylated ghrelin and leptin in adolescent athletes with amenorrhea, eumenorrheic athletes and controls: A cross-sectional study. Clin. Endocrinol. 2008, 69, 628-633. [CrossRef] [PubMed]

15. Rämson, R.; Jürimäe, J.; Jürimäe, T.; Mäestu, J. The influence of increased training volume on cytokines and ghrelin concentration in college level male rowers. Eur. J. Appl. Physiol. 2008, 104, 839-846. [CrossRef] [PubMed]

16. Melin, A.; Tornberg, A.B.; Skouby, S.; Moller, S.S.; Sundgot-Borgen, J.; Faber, J.; Sidelmann, J.J.; Aziz, M.; Sjödin, A. Energy availability and the female athlete triad in elite endurance athletes. Scand. J. Med. Sci. Sports 2015, 25, 610-622. [CrossRef] [PubMed]

17. Weir, J.V.B. New methods for calculating metabolic rate with special reference to protein metabolism. J. Physiol. 1949, 109, 1-9. [CrossRef] [PubMed]

18. Probst, M.; Vandereycken, W.; Van Coppenolle, H.; Vanderlinden, J. The Body Attitude Test for patients with eating disorder: Psychometric characteristics of a new questionnaire. Eat. Disord. 1995, 3, 133-144. [CrossRef]

19. Probst, M.; Van Coppenolle, H.; Vandereycken, W. Further experience with the Body Attitude Test. Eat. Weight Disord. 1997, 2, 100-104. [CrossRef] [PubMed]

20. Horn, E.; Gergen, N.; McGarry, K.A. The female athlete triad. R. I. Med J. 2014, 97, 18-21.

21. Sundgot-Borgen, J.; Torstveit, M.K. Aspects of disordered eating continuum in elite high-intensity sports. Scand. J. Med. Sci. Sports 2010, 2, 112-121. [CrossRef]

22. Varnes, J.R.; Stellefson, M.L.; Janelle, C.M.; Dorman, S.M.; Dodd, V.; Miller, M.D. A systematic review of studies comparing body image concerns among female college athletes and non-athletes, 1997-2012. Body Image 2013, 10, 421-432. [CrossRef]

23. Kang, M.H.; Choue, R. Relationships of body image, body stress and eating attitude, and dietary quality in middle school girls based on their BMI. Korean J. Nutr. 2010, 43, 3. [CrossRef]

24. Salm, E.; Käärik, E.; Kaarma, H. The Growth Charts of Estonian Schoolchildren. Comparative Analysis. Papers on Anthropology, 22nd ed.; Arend, A., Ed.; University of Tartu Press: Tartu, Estonia, 2013; pp. 171-183.

25. Liechty, J.M. Body image distortion and three types of weight control behaviors among non-overweight girls in the U.S. J. Adolesc. Health 2010, 47, 176-182. [CrossRef] [PubMed] 
26. Souki, A.; Arraíz, N.; Prieto, C.; Pérez Jiménez, F.; Valero, P.; Amell, A.; Cano-Ponce, C. Association between resistin serum levels and dimension and body composition variables in children and adolescents. Rev. Med. Chile 2016, 144, 307-316. [CrossRef] [PubMed]

27. Marcelino-Rodriguez, I.; Gonzalez, D.A.; Aleman-Sanchez, J.J.; Diaz, B.B.; Rodriquez Perez, M.C.; Gannar, F.; Coello, S.D.; Fennandez, F.J.C.; de Leon, A.C. Inverse association of resistin with physical activity in the general population. PLoS ONE 2017, 12, e0182493. [CrossRef] [PubMed]

28. Roupas, N.D.; Mamali, I.; Armeni, A.K.; Markantes, G.K.; Theodoropoulou, A.; Alexandrides, T.; Leglise, M.; Markou, K.B.; Georgopoulos, N.A. The influence of intensive physical training on salivary adipokine levels in Elite Rhythmic Gymnasts. Horm. Metab. Res. 2012, 44, 980-986. [CrossRef]

29. Lehto, S.M.; Huotari, A.; Niskanen, L.; Tolmunen, T.; Koivumaa-Honkanen, H.; Honkalampi, K.; Ruotsalainen, H.; Herzig, K.H.; Viinamäki, H.; Hintikka, J. Serum adiponectin and resistin levels in major depressive disorder. Acta. Psychiatr. Scand. 2010, 121, 209-215. [CrossRef]

30. Zeugmann, S.; Quante, A.; Heuser, I.; Schwarzer, R.; Anghelescu, I. Inflammatory biomarkers in 70 depressed inpatients with and without the metabolic syndrome. J. Clin. Psychiatr. 2010, 71, 1007-1016. [CrossRef]

31. Karageorgiou, V.; Furukawa, T.A.; Tsigkaropoulou, E.; Karavia, A.; Gournellis, R.; Soureti, A.; Bellos, I.; Douzenis, A.; Michopoulos, I. Adipokines in anorexia nervosa: A systematic review and meta-analysis. Phychoneuroendocrinol 2020, $112,104485$. [CrossRef]

32. Klinkowski, N.; Korte, A.; Pfeiffer, E.; Lehmkuhl, U.; Salbach-Andrae, H. Psychopathology in elite rhythmic gymnasts and anorexia nervosa patients. Eur. Child Adolesc. Psychiatry 2008, 17, 108-113. [CrossRef]

33. Bahls, S.; Bahls, F.R.C. Depressão na adolescência: Características clínicas. Int. Psicol. 2002, 6, 49-57. [CrossRef]

34. Amaral, A.C.S.; Ferreira, M.E.C. Body dissatisfaction and associated factors among Brazilian adolescents: A longitudinal study. Body Image 2017, 22, 32-38. [CrossRef]

35. Filho, L.C.S.; Batista, R.F.L.; Cardoso, V.C.; Simões, V.M.F.; Santos, A.M.; Coelho, S.J.D.D.A.C.; Silva, A.A.M. Body image dissatisfaction and symptoms of depression disorder in adolescents. Braz. J. Med. Biol. Res. 2021, 54, e10397. [CrossRef] [PubMed]

36. Beyon, H. Association between weight misperception patterns and depressive symptoms in Korean young adolescents: National cross-sectional study. PLoS ONE 2015, 10, 1-9. [CrossRef]

37. Rodriguez, N.R.; DiMarco, N.M.; Langley, S. American Dietetic Association, Dietitians of Canada, \& American College of Sports Medicine. Position of the American dietetic association, dietitians of Canada and the American college of sports medicine: Nutrition and athletic performance. J. Am. Diet. Assoc. 2009, 109, 509-527. [PubMed] 